\section{Coming Events}

2017

Understanding Biology Through

Structure 2017

May 13-17, 2017

Santa Fe, NM

https://conferences.newmexicoconsortium.org/

conferences/ubts 17

Annual Meeting of American

Crystallographic Association

May 26-30, 2017

New Orleans, LA

www.amercrystalassn.org/2017-meeting-homepage

ASM Microbe 2017

June 1-5, 2017

New Orleans, LA

www.asm.org/index.php/asmmicrobe-2017

Scandem 2017 - Annual Conference of the Nordic Microscopy Society

June 5-9, 2017

Reykjavik, Iceland

http://scandem2017.hi.is

Microscience Microscopy Congress and EMAG2017 (mmc2017)

July 3-6, 2017

Manchester, UK

www.mmc-series.org.uk

Denver X-Ray Conference

July 31-August 4, 2017

Big Sky, MT

www.dxcicdd.com

Microscopy \& Microanalysis 2017

August 6-10, 2017

St. Louis, MO

www.microscopy.org

\section{8}

Microscopy \& Microanalysis 2018

August 5-9, 2018

Baltimore, MD

www.microscopy.org

\section{9}

Microscopy \& Microanalysis 2019

August 4-8, 2019

Portland, OR

www.microscopy.org

\section{0}

Microscopy \& Microanalysis 2020

August 2-6, 2020

Milwaukee, WI

www.microscopy.org

\section{1}

Microscopy \& Microanalysis 2021

August 1-5, 2021

Pittsburgh, PA

www.microscopy.org

\section{2}

Microscopy \& Microanalysis 2022

July 31-August 4, 2022

Portland, OR

www.microscopy.org

More Meetings and Courses

Check the complete calendar near the back of this magazine.

\title{
Incubation of Dinosaur Eggs Determined by Microscopy
}

\author{
Stephen W. Carmichael \\ Mayo Clinic, Rochester, MN 55905 \\ carmichael.stephen@mayo.edu
}

Very little is known of the embryology of dinosaurs. Since birds are directly descended from dinosaurs, it has been assumed that dinosaurs and birds develop similarly. An important aspect of avian development is that birds produce relatively small numbers of large eggs with remarkably short incubation periods (average 11 to 85 days). This short incubation is advantageous to a species because the eggs, and any attending parent, are less exposed to predation and other environmental challenges than if the period were longer. It has been assumed that dinosaurs also had a short incubation period, which birds inherited. A recent study by Gregory Erickson, Darla Zelenitsky, David Kay, and Mark Norell has not only shown that this assumption is incorrect, but the authors present a new way to determine the incubation period of fossilized dinosaurs, which has important implications.

Erickson et al. [1] examined the teeth of two species of dinosaurs, Protoceratops andrewsi (a horned herbivore) and Hypocerosaurus stebingeri (a duckbilled dinosaur) recovered from 75 million year old sediments in Alberta, Canada, and the Gobi desert of Mongolia, respectively. It is known from studies of embryonic teeth (including those from embryos) in crocodilians and humans that incremental lines of von Ebner reflect diurnal pulses of mineralization during tooth formation. Thus counting these lines gives a reliable estimate of the number of days it took a tooth to form. An extrapolation from the period of tooth formation allows the incubation period to be determined. Erickson et al. showed that (1) lines of von Ebner are present in embryonic dinosaur teeth, (2) counts and data on lines of von Ebner revealed different incubation periods for these

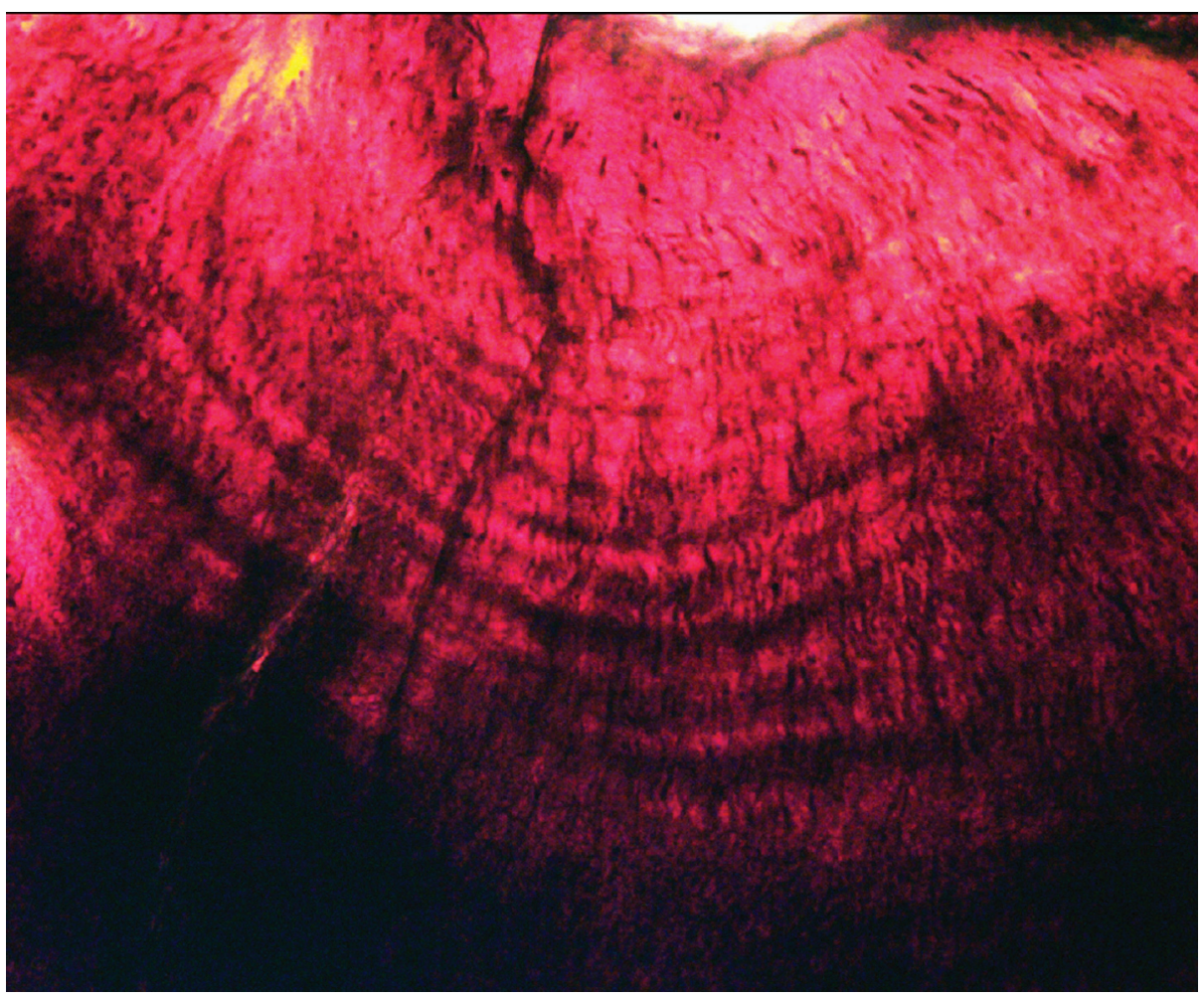

Figure 1: Incremental lines of von Ebner in the dentine of an embryonic Hypacrosaurus stebingeri tooth. Approximately 30 days of dentine deposition is represented in this image. Transverse plane, polarized microscopy. Image width $=310 \mu \mathrm{m}$. Credit: Gregory M. Erickson. Ph. D. 


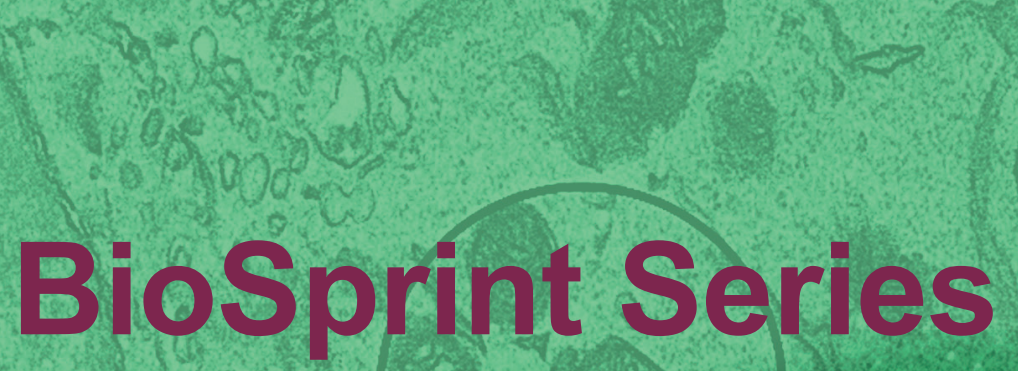

Fast 1.M Imaging for Life Sciences

\section{Ideal Magnification Factors for TEM Imaging}

-12,16, and 29 Megapixel Scientific Sensors

- Focus Friendly Readout Speeds

- Low Maintenance Modular Design

- High Performance Lens

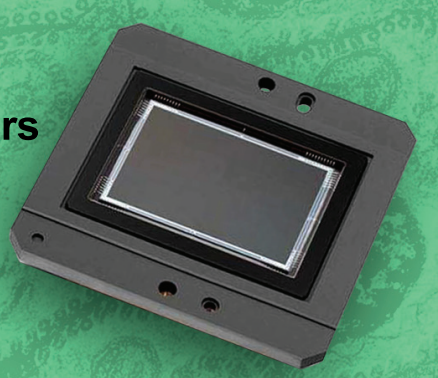

Over 2000 AMT Systems worldwide operate with fast and reliable service and support!

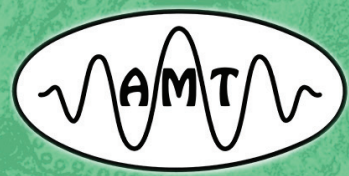

\section{Advanced Microscopy Techniques}

242 West Cummings Park, Woburn, MA 01801

Tel: (978)774-5550 - Fax: (978)739-4313

sales@amtimaging.com

www.amtimaging.com 
two species of dinosaurs whose eggs span nearly the entire size range reported for dinosaurs, and (3) they could test whether these dinosaurs show typical rapid avian incubation times or primitive slow reptilian development. This allowed them to explore ramifications of their results with regard to the origin of modern avian incubation and survivorship through the Cretaceous-Paleogene (K-Pg) extinction event that occurred about 66 million years ago.

Using polarized (transmitted light) petrographic microscopy on sections of teeth to measure lines of von Ebner in transverse and longitudinal planes, Erickson et al. could accurately measure the width and number of lines (Figure 1). They also used incidental light (direct illumination) dissection microscopy on fractured teeth within the jaw to examine longitudinal growth-line expression.

In a significant departure from earlier assumptions, Erickson et al. showed that the incubation period of dinosaurs is approximately twice as long as birds with similarly-sized eggs. This makes dinosaur reproduction more vulnerable to interference and may be related to the failure of dinosaurs to compete effectively for vacated ecologic niches that occurred after the K-Pg extinction event, offering another reason why dinosaurs became extinct. This discovery is important and may help explain why birds survived and dinosaurs became extinct after an asteroid struck Earth 66 million years ago. [2]

\section{References}

[1] GM Erickson et al., Proc Nat Acad Sci 114 (2017) 540-45.

[2] The author gratefully acknowledges Dr. Gregory Erickson for reviewing this article.
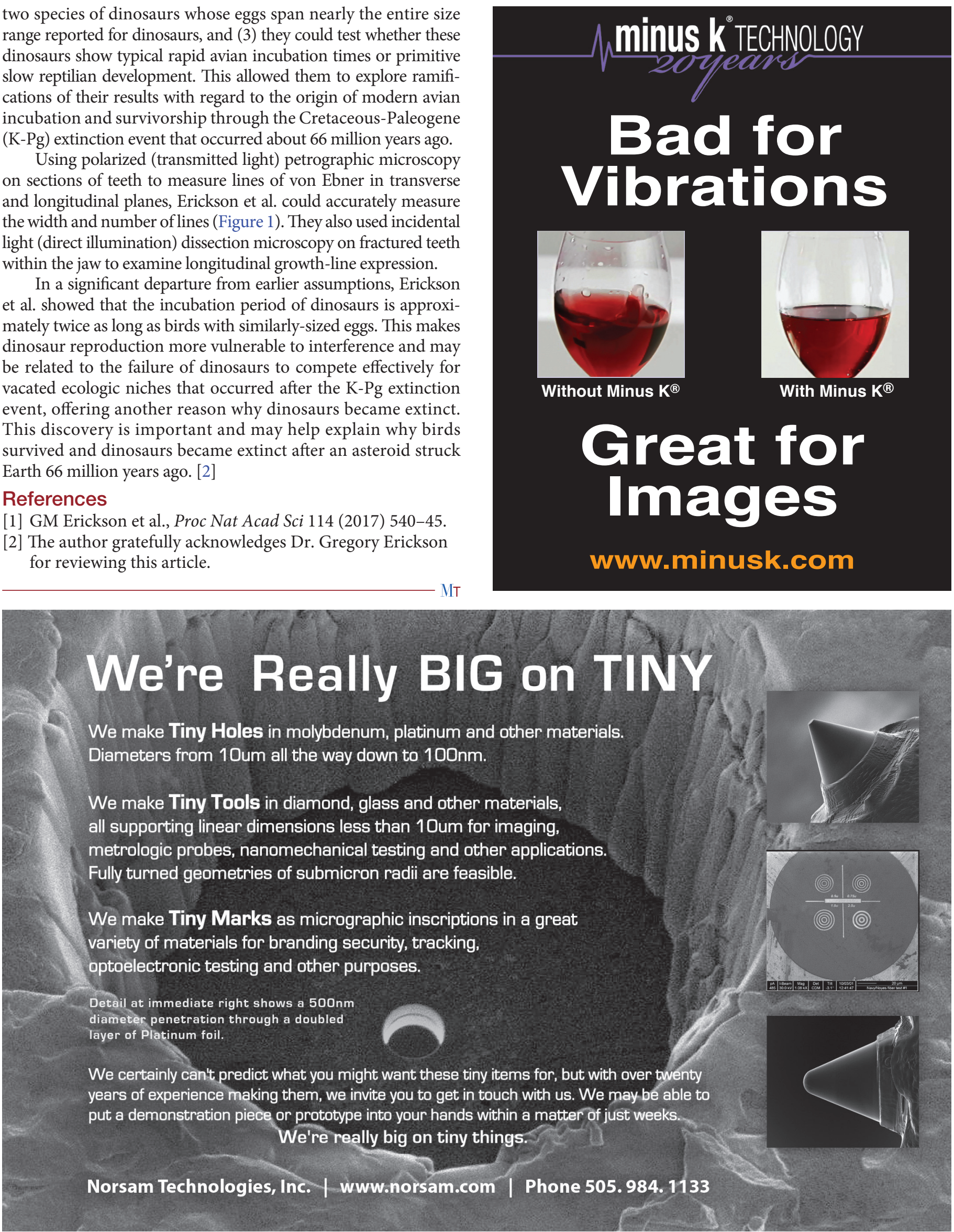


\section{Incomparable...}

...and still innovating

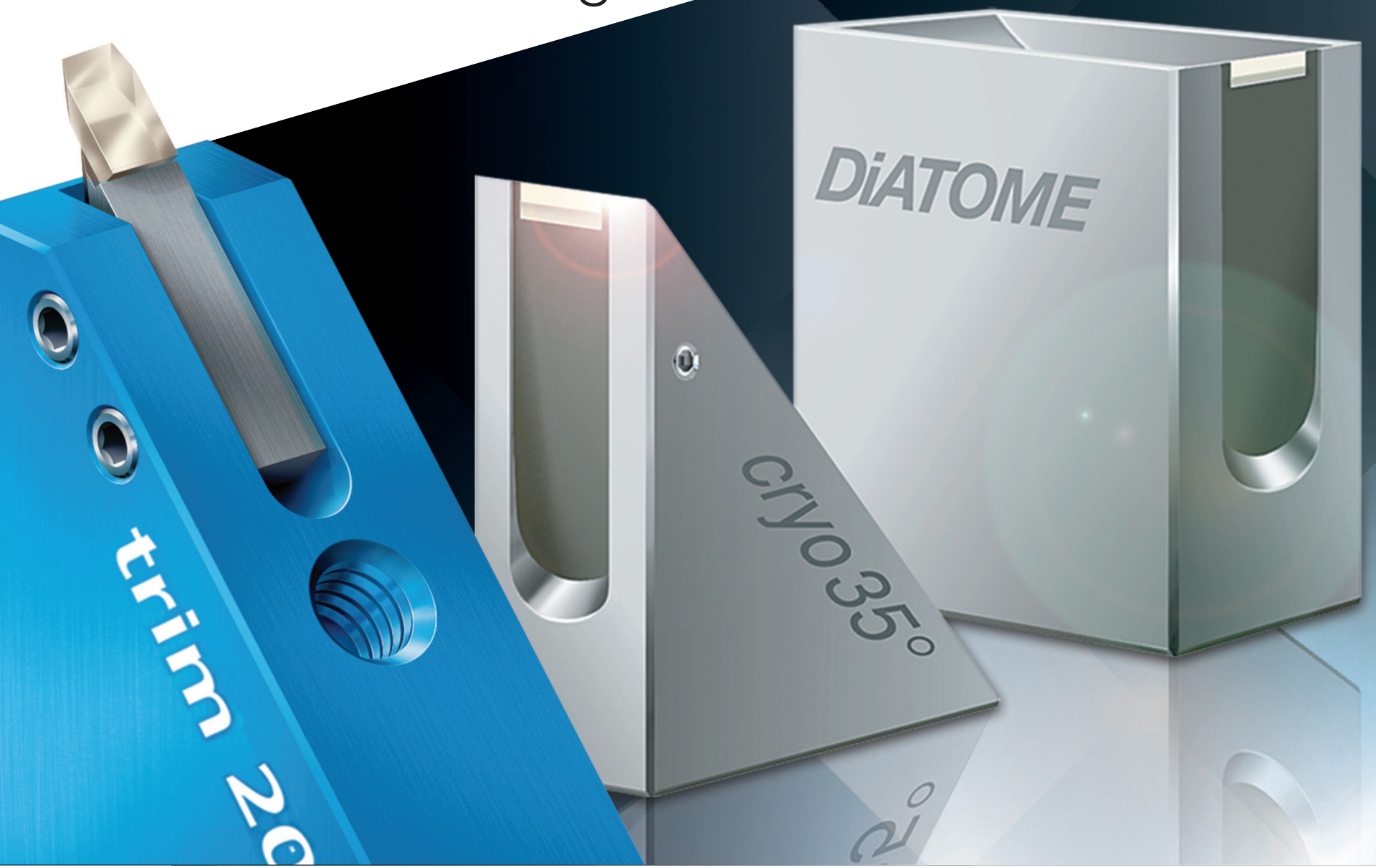

\section{DIATOME diamond knives}

ultra $45^{\circ} \cdot$ cryo $\cdot$ histo ultra $35^{\circ}$ - histo jumbo cryo immuno • ultra sonic ultra AFM \& cryo AFM trimtool 20 - trimtool 45 trimtool 90

Over 40 years of development, manufacturing, and customer service

\section{DIATOME U.S.}

P.0. Box $550 \bullet 1560$ Industry Rd. • Hatfield, Pa 19440 Tel: (215) 412-8390 • Fax: (215) 412-8450

email: sgkcck@aol.com •www.emsdiasum.com

\section{Free customer service}

Sectioning tests with biological and material research specimens of all kinds. We send you the sections along with the surfaced sample, a report on the results obtained and a recommendation of a suitable knife. Complete discretion when working with proprietary samples.

Re-sharpening and reworking service

A re-sharpened Diatome diamond knife demonstrates the same high quality as a new knife. Even knives purchased in previous years can continue to be re-sharpened. The knives can be reworked into another type of knife for no extra charge, e.g. ultra to cryo or $45^{\circ}$ to $35^{\circ}$.

\section{Exchange service}

Whenever you exchange a knife we offer you a new DiATOME knife at an advantageous price. 